\title{
Procedural sedation for intra-articular corticosteroid injections in juvenile idiopathic arthritis (JIA) should be a standard of care
}

\author{
Serena Pastore • Giulia Gortani • Andrea Taddio • \\ Egidio Barbi
}

Received: 7 October 2013 / Accepted: 11 December 2013 /Published online: 3 January 2014

(C) Springer-Verlag Berlin Heidelberg 2014

We appreciated the report by Casado et al. regarding sedation for intra-articular corticosteroid injections (IACI) in juvenile idiopathic arthritis (JIA) [2]. However we cannot share their conclusions since they compared Sevoflurane sedation with no sedation, without considering other possible approaches. In our institute, non-anesthesiologists-administered propofol (NAAP) and nitrous oxide $\left(\mathrm{N}_{2} \mathrm{O}\right)$ are routinely used for sedation for IACI. The safety and efficacy of NAAP in defined settings after proper training and patient selection is reported in literature [3]. In the period between 2000 and 2013 in our institute, 461 patients underwent IACI with NAAP without any relevant complication. Inhaled $\mathrm{N}_{2} \mathrm{O}$ has also been shown to provide effective and safe sedation for JIA children undergoing IACI [1]. Since 2012, $\mathrm{N}_{2} \mathrm{O}$ was offered by us to children older than 6 scheduled for joint injection. We performed 43 procedures in 35 patients (median age, 11 years; range, 6-18). Premedication with oral midazolam $(0.5 \mathrm{mg} / \mathrm{kg})$ was used in $23 / 35$ patients. All patients completed a visual analogue pain scale (VAS; $0-10 \mathrm{~cm}$ ) immediately after the procedure and after 30 and $60 \mathrm{~min}$. Ramsay score and recall of the procedure were used to assess the level of sedation. Median Ramsay score was 2 (range, 1-3), corresponding to a quiet and collaborating patient. No pain (VAS 0) was reported in 27/35 patients immediately after the procedure and in $28 / 35$ patients after $60 \mathrm{~min}$. Median reported VAS was 4 (range, 0-10) immediately after the procedure, 3 after $30 \mathrm{~min}$ (range, $0-8$ ) and 1.5 after $60 \mathrm{~min}$ (IQR, 1-2.5; range, 0-7). Vomiting occurred in one patient. No other adverse event was observed. Six out of 35 patients had memory of the procedure. Avoidance of pain and discomfort during hospitalization is a priority for children with chronic illness: procedural sedation, either deep or moderate, can be safely performed in JIA children by trained pediatricians and should be considered as a standard of care.

Conflict of interest The authors declare that there are no conflicts of interest.

\section{References}

1. Annequin D, Carbajal R, Chauvin P, Gall O, Tourniaire B, Murat I (2000) Fixed $50 \%$ nitrous oxide oxygen mixture for painful procedures: a French survey. Pediatrics 105(4):E47

2. Casado R, Lumbreras J, de Inocencio J, Remesal A, Merino R, GarcíaConsuegra J (2013) Sedation for intra-articular corticosteroid injections in juvenile idiopathic arthritis: the views of patients and their parents. Eur J Pediatr 172(10):1411-1413

3. Couloures KG, Beach M, Cravero JP, Monroe KK, Hertzog JH (2011) Impact of provider specialty on pediatric procedural sedation complication rates. Pediatrics 127(5):e1154-e1160 